\title{
Nanocrystalline gold catalysts: A reflection on catalyst discovery and the nature of active sites
}

\author{
Graham J. Hutchings \\ www.goldbulletin.org \\ Cardiff Catalysis Institute, School of Chemistry, \\ Cardiff University, Cardiff, CF10 3AT, UK
}

\section{Introduction}

This article is written in memory of David Thompson, someone who in recent years played a significant part in the promotion of the topic of catalysis by gold; indeed he played a leading role at the outset with his seminal reviews, co-authored with Geoff Bond $(1,2)$, where they highlighted the great potential of gold as a catalyst. My interactions with David started in 1982 when he visited AECI South Africa and we discussed catalysis by metals; but we really started interacting on gold catalysis since 1996 and he was one of the major contributors to the very successful EU research collaboration AURICAT from 2002-2006.

The article is based on a plenary lecture delivered by the author at the close of the Gold 2009 conference in Heidelberg. The theme developed in the lecture concerned the possible nature of active sites in gold catalysis in three reactions:

- acetylene hydrochlorination

- CO oxidation

- direct synthesis of hydrogen peroxide.

Taylor was the first to originate the concept of the active site in catalysis (3) in 1925. Since then it has become a concept that is well developed in all branches of catalysis. However, active sites at present are best defined and consequently the mechanisms of the reaction being catalysed best understood for homogeneous and biological catalysis. It is the well defined molecular nature of these active sites, coupled with advances in molecular spectroscopy and diffraction methodologies that have enabled this deeper understanding of catalysis in these systems to be achieved. In contrast, in heterogeneously catalysed systems the situation is much more complex as we deal with highly complex mixtures of structures that co-exist in the active catalyst. There may in many cases not just be a single structure for an active site, rather there may be a range of structures which display a broad spectrum of activities and specificities. For example in heterogeneously catalysed oxidation catalysis different sites are considered responsible for the formation of the selective and non-selective products. A further complication is that the active sites might be present in exceeding low concentrations on the surface of the catalyst. As most of the atoms present in the solid sample are located in the bulk this presents a further challenge in understanding the nature of the active site in heterogeneously catalysed reactions. This has led over the preceding decades to the design of model systems using single crystals and well defined surface as these can be interrogated using modern surface spectroscopy. The understanding of gold catalysed heterogeneously catalysed reactions has been hampered by all these constraints. One of the most well studied reactions concerns the oxidation of $\mathrm{CO}$ using nanocrystalline gold, discovered by Haruta (4). The identification of the mechanism of reaction and the nature of the active site has instigated numerous studies $(5,6)$. Bond and Thompson have so far given one of the best descriptions of the possible reaction mechanism based on their detailed analysis of the available literature (2). However, the mechanism has not been further refined as the nature of the active site remains a matter of debate. Indeed, there is the added complexity that different gold may have different active sites on different oxide supports, as defect formation is more facile with some oxides. A number of proposals emphasize the size and morphology of the gold particle and its interface with the support $(1,8)$, whereas others postulate that the metal oxidation state $(9,10)$ and support material can have strong effects $(1,11)$. Most of the fundamental insights into this reaction have come from well defined model studies (12-15) in which specific structures are tailor-made (14). The difficulty is always 
linking these informative model studies to those carried out on real catalysts, which are inherently more complex. Recently the advent of aberrationcorrected electron microscopy has enabled further insights to be gained since $A u$, due to its high nuclear mass or Z-contrast on oxides such as $\mathrm{TiO}_{2}$ and $\mathrm{Fe}_{2} \mathrm{O}_{3}$, has proved a particularly good system for study. For the $\mathrm{Au} / \mathrm{Fe}_{2} \mathrm{O}_{3}$ catalyst a detailed study has shown that, in this case, the activity is associated with small bi-layer structures comprising seven to ten gold atoms (16); however, this may not be the case for other reactions/catalyst formulations. The identification that such small structure may be the active site provides a bridge between well defined model systems, theoretical studies and real catalysts.

In the present paper the remarks on the nature of the active site in gold catalysis will be restricted to the hydrochlorination of acetylene where the active site is shown to be associated with cationic gold rather than elemental gold. Recent advances in gold catalysed CO oxidation (17) and the synthesis of hydrogen peroxide (18) have been reviewed but the hydrochlorination of alkynes remains a fascinating reaction, and a reaction for which gold can be considered to be the best catalyst.

\section{Acetylene hydrochlorination}

While the oxidation of $\mathrm{CO}$ on gold, which is also a reaction for which gold is the best catalyst, has been extensively studied, the hydrochlorination of acetylene to form vinyl chloride (VCM) has received much less attention. One reason for this may be that it is not an easy reaction to study in a laboratory environment. We have recently made some new investigations of this reaction (19-21) and now can comment on the nature of the active site for this reaction.

\section{Correlation of activity with the standard electrode potential}

The observation that gold, and in particular cationic gold, is the best catalyst for this reaction stems from an analysis of the activity of a large number of carbon-supported metal chloride catalysts which was shown to correlate with the standard electrode potential (22). These supported metal chlorides did not include gold and it was on the basis of this correlation that it was predicted that cationic gold would be the best catalyst for this reaction (22), and indeed this was subsequently confirmed (23-25). The correlation with the standard electrode potential has recently been confirmed (21) for catalysts containing 1 wt\% metal (Figure 1) based on the initial rate of reaction. There is a linear correlation

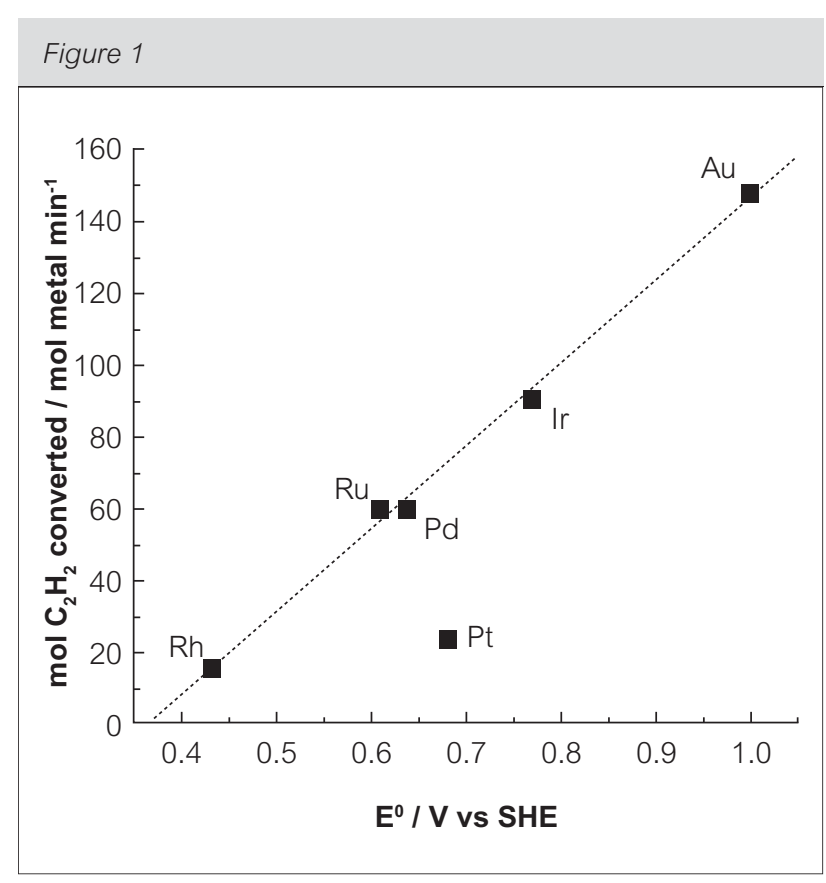

Correlation between initial acetylene conversion versus the standard electrode potential of $1 \mathrm{wt} \%$ metals supported on carbon. Potentials are obtained from the reduction potentials of the following chloride salts $\left(\mathrm{RhCl}_{6}\right)^{3-},\left(\mathrm{RuCl}_{5}\right)^{2-}, \mathrm{PdCl}_{2},\left(\mathrm{PtCl}_{6}\right)^{2-}$, $\left(\mathrm{IrCl}_{6}\right)^{3-},\left(\mathrm{AuCl}_{4}\right)^{-}$to the corresponding metals (21)

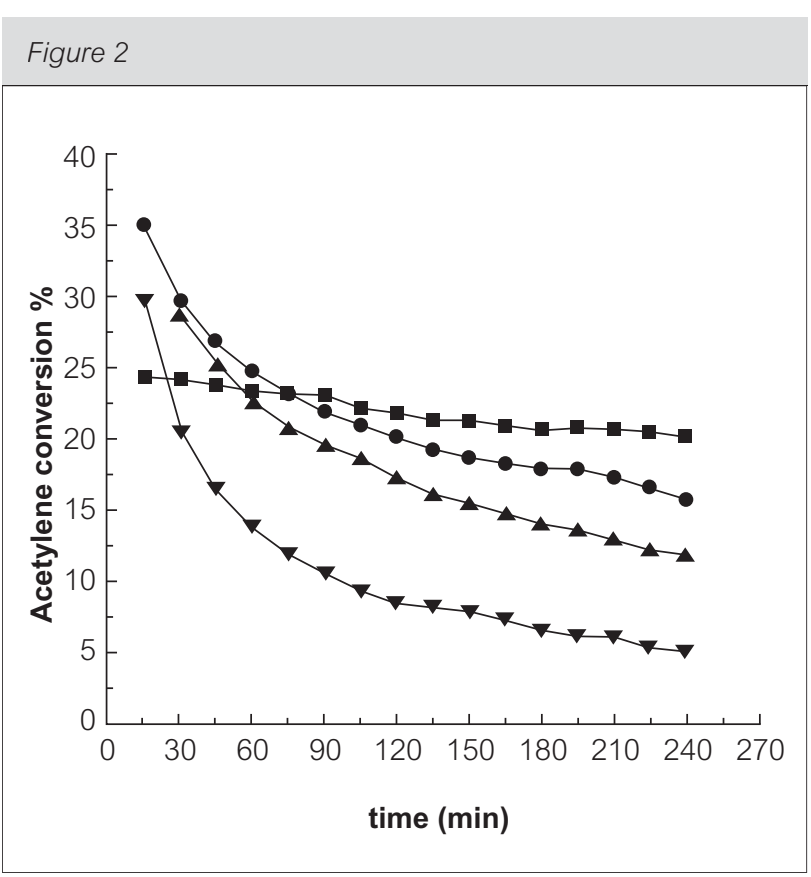

Acetylene conversion for Au and Au/Pd catalysts on carbon for low palladium loading: (ם) Au, (O)AulPd 99/1, (A)AulPd95/5 and $(\boldsymbol{\nabla})$ Au/Pd 90/10 
with the standard electrode potential, and in this case we have used the data for the chlorides (which are different from previously published correlations which were based on the metals) which, with the exception of $\mathrm{Pt}$, have initial oxidation state II or III and the reduction $\mathrm{M}^{\mathrm{n}+}$ to $\mathrm{M}^{0}$ is considered. For $\mathrm{Pt}$ which has an initial oxidation state of IV, the reduction $\mathrm{Pt}^{4+}$ to $\mathrm{Pt}^{2+}$ has been used since the reaction is a two electron process, it is considered unlikely that reduction to the metal will occur. However, it is notable that the initial activity for Pt is much lower than that expected from the correlation, and this may be due to very rapid deactivation of this catalyst but it should be noted that Pt has a low propensity to form complexes with alkynes and therefore could be expected to be a poorer catalyst.

It has been shown for many reactions catalysed by gold that the addition of palladium provides a synergistic promotion in the activity. This is particularly marked in the oxidation of some alcohols (26) and the direct synthesis of hydrogen peroxide (27). Since supported palladium and gold chlorides are active separately for this reaction (Fig. 1) we studied acetylene hydrochlorination over AuPd catalysts comprising $1 \mathrm{wt} \%$ metal in total but with low amounts of $\mathrm{Pd}$ present. At this low level the AuPd catalysts were found to be alloyed (21) and the rate of hydrochlorination did show some initial enhancement in activity (Fig. 2) although the effect

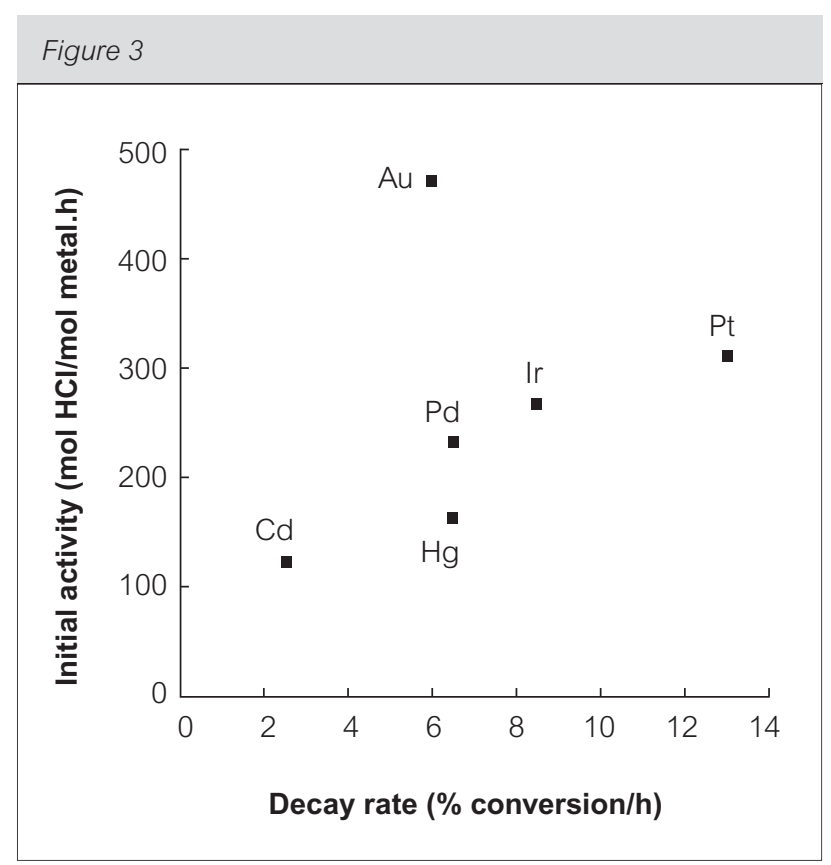

Initial rate for acetylene hydrochlorination plotted against the deactivation rate for carbon-supported metal catalysts. Au is the most stable catalyst was short lived. The VCM selectivity of the Au/C catalyst is almost $100 \%$ and only trace amounts of other products (e.g. dichloroethane) can be observed. However, for the Au/Pd catalysts this was not the case; the initial selectivity to VCM decreased with increasing $\mathrm{Pd}$ content (21). Pd is a known catalyst for dehydrochlorination reaction and the deactivation observed was partly due to oligomer formation. Hence the enhancement in initial rate was due to promotion of a non selective reaction and not associated with the selective hydrochlorination reaction. Addition of palladium, or indeed any metal, to gold, as a homogeneous alloy if alloy formation is feasible, would be expected to decrease the standard electrode potential (21) and consequently, if the correlation holds, would be expected to decrease the activity of gold. We showed this was the case for several metals (21) and consequently to date supported gold catalysts appear to be the best catalysts for acetylene hydrochlorination.

\section{Origin of deactivation in supported gold catalysts}

Unfortunately, supported gold catalysts show steady deactivation for acetylene hydrochlorination with time on stream (Figure 2); however, supported gold catalysts are the most stable for this reaction (Fig. 3). Deactivation is marked in two temperature regions and the most stable activity is observed at a

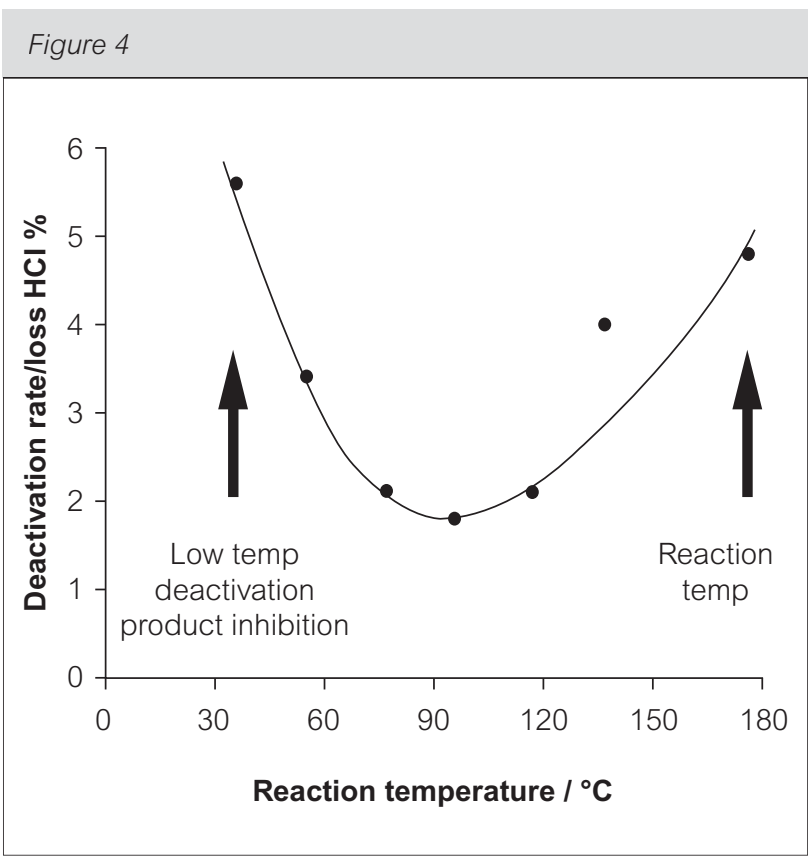

Effect of reaction temperature on the deactivation of AulC catalysts for acetylene hydrochlorination 


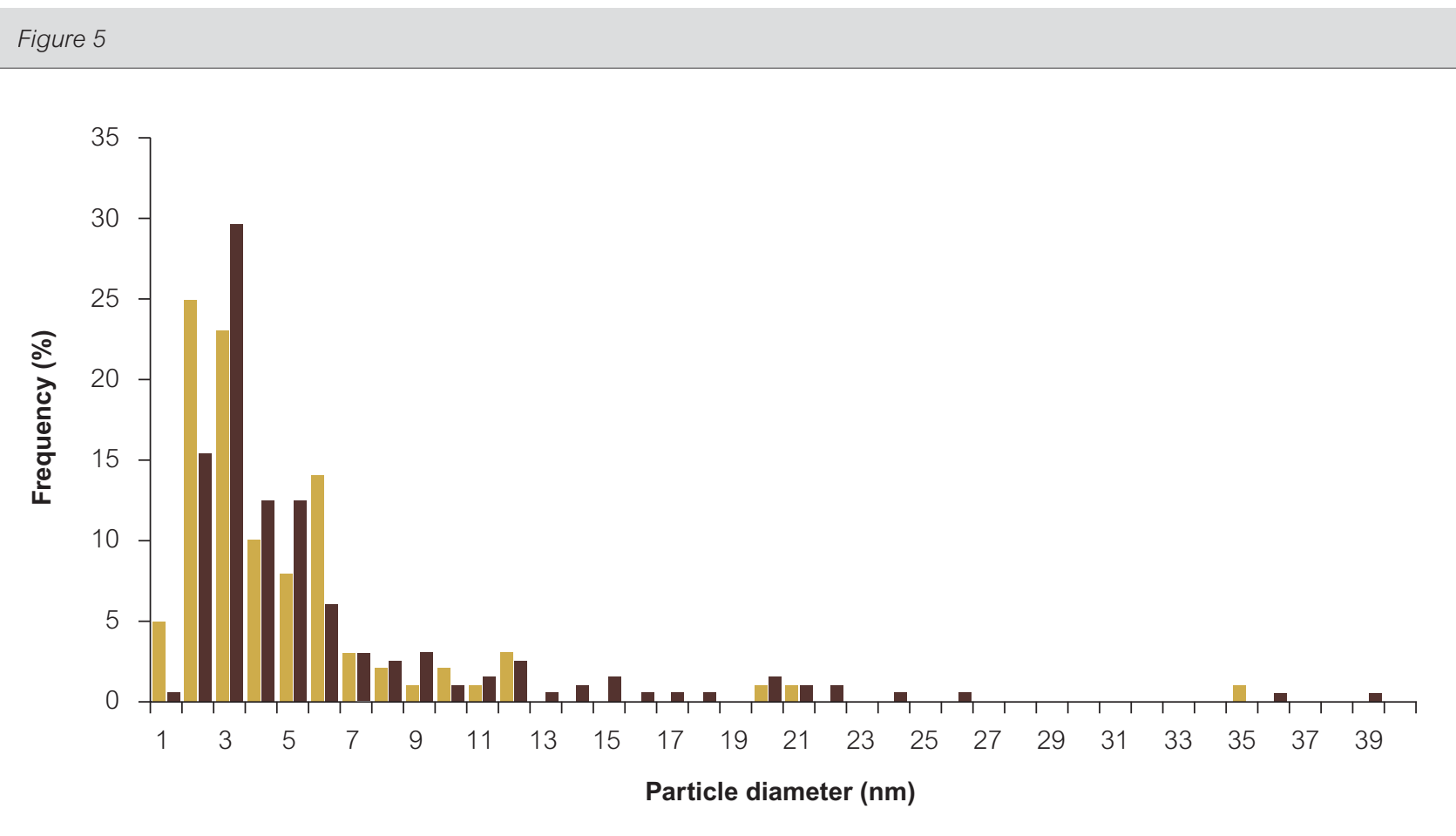

Au particle size distributions of $1 \mathrm{wt} \%$ AulC before and after use as a catalyst for acetylene hydrochlorination (22), filled columns pre-reaction and open columns post-reaction, showing a slight increase in the particle size after the reaction from 4.8 to $5.9 \mathrm{~nm}$

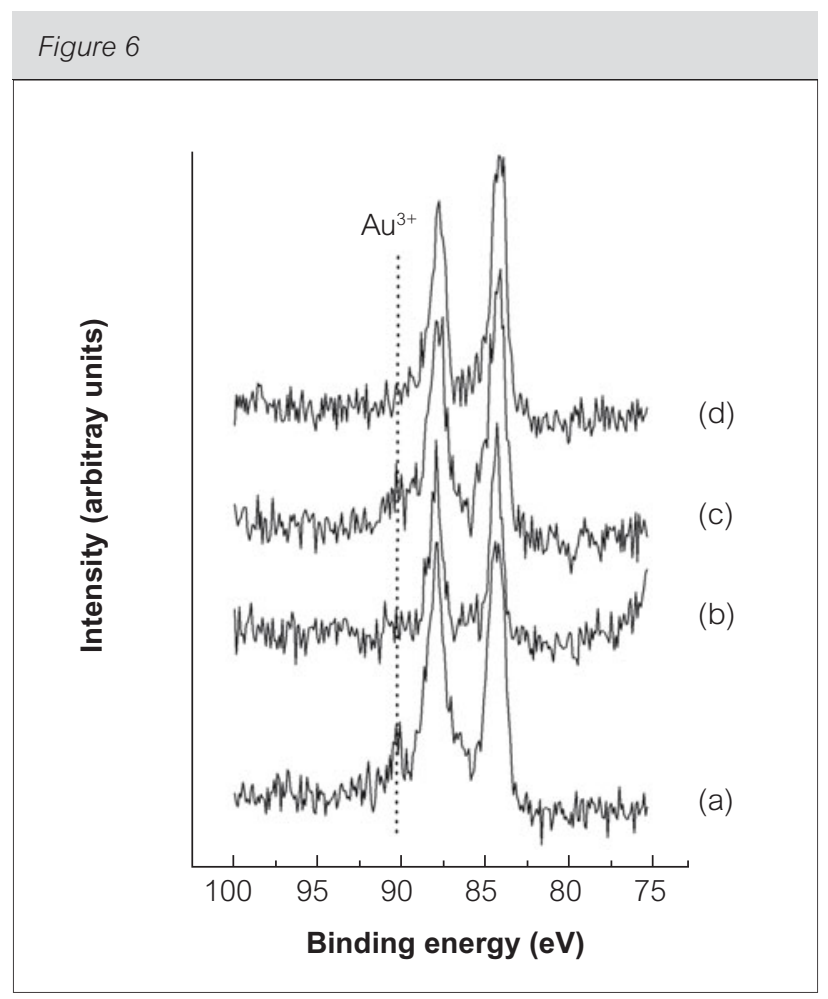

Au $4 f$ XPS spectra of Au/C catalysts, (a) before reaction it is possible to detect the presence of $\mathrm{Au}^{3+}$ while (b) after reaction $\mathrm{Au}^{3+}$ is reduced, (c) after reactivation with aqua regia it is possible to detect $\mathrm{Au}^{3+}$ while (d) after reaction $\mathrm{Au}^{3+}$ is reduced (19) temperature of $100^{\circ} \mathrm{C}$ but unfortunately the catalysts are not sufficiently active at this temperature (Fig. 4). Low temperature deactivation is due to product inhibition but at the reaction temperature of $180^{\circ} \mathrm{C}$ deactivation could be due to sintering of the gold nanoparticles. Examination of fresh and used catalysts using transmission electron microscopy (20) has shown that there is a small amount of sintering observed (Fig. 5) but this is not considered to be the main cause of deactivation. However, it is clear that there are a number of morphologies present in the supported $\mathrm{Au} / \mathrm{C}$ catalyst and the question remains as to which of these are the active structures. However, both XPS and Mössbauer spectroscopy show that most of the gold present in the catalysts (and observed in Fig. 5) is metallic and only a relatively small fraction is present in the active cationic form. The main cause of deactivation is the reduction of $\mathrm{Au}^{3+}$ which is confirmed by XPS spectroscopy (Fig. 6) and Mössbauer spectroscopy (Fig. 7). Indeed we have shown that Au/C catalysts can be reactivated by boiling in aqua regia for a short period (19) and this increases the amount of $\mathrm{Au}^{3+}$ present in the catalysts (Figs. 6 and 7). 


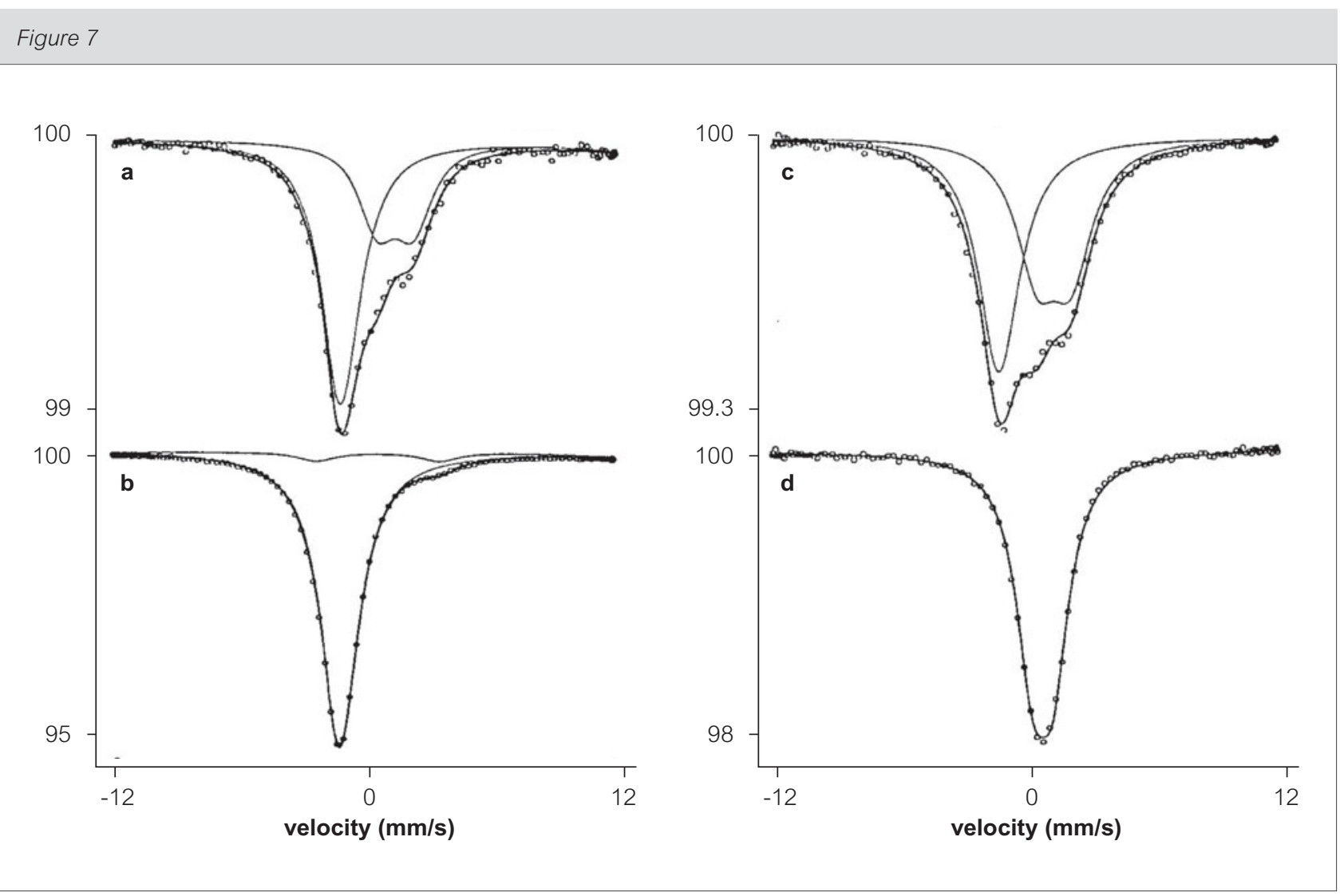

${ }^{197} \mathrm{Au}$ Mössbauer spectra of (a) $2 \% \mathrm{HAuCl}_{4} / \mathrm{C}$ adsorbed on activated carbon from an aqua regia solution, (b) the same catalyst after deactivation at $180^{\circ} \mathrm{C}$ for $6 \mathrm{~h}\left(\mathrm{GHSV}=1140 \mathrm{~h}^{-1}, \mathrm{C}_{2} \mathrm{H}_{2}: \mathrm{HCl}=1: 1.1\right)$, (c) a sample of the same type after reactivation by boiling in aqua regia, and (d) crystalline $\mathrm{HAuCl}_{4} \cdot \mathrm{xH}_{2} \mathrm{O}(25)$

Figure 8

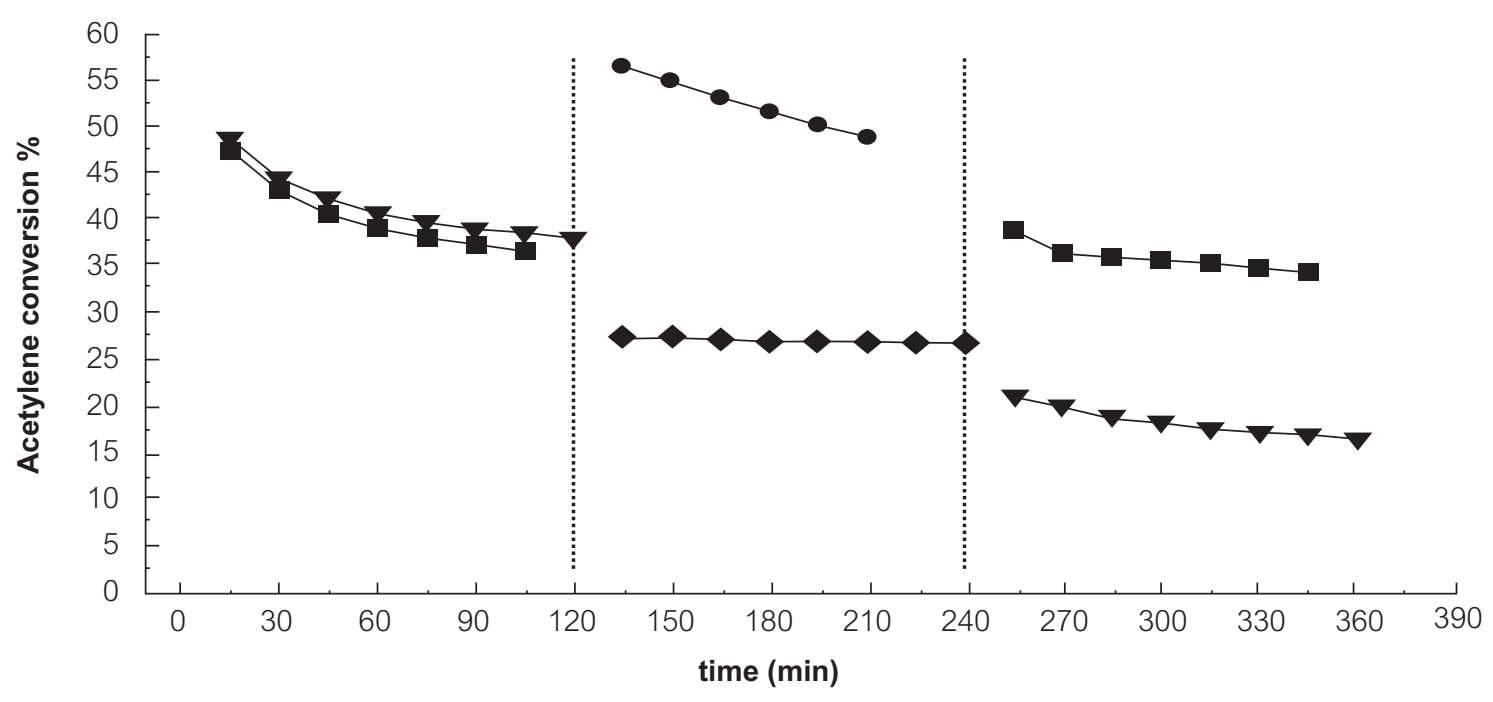

Sequential flow experiments to evaluate the effect of each reactant for the hydrochlorination reaction of acetylene over Au/C catalyst. (Experiment 1A: $\mathrm{C}_{2} \mathrm{H}_{2} / \mathrm{HCl}(2 h) \rightarrow \mathrm{He} / \mathrm{HCl}(2 h) \rightarrow \mathrm{C}_{2} \mathrm{H}_{2} / \mathrm{HCl}(2 h) ;($ Experiment 2: $) \mathrm{He} / \mathrm{HCl}(2 h) \rightarrow \mathrm{C}_{2} \mathrm{H}_{2} / \mathrm{HCl}(2 h) \rightarrow \mathrm{He} / \mathrm{HCl}(2 h)$

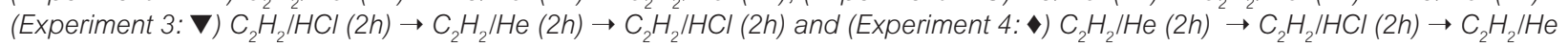
(2h) (20) 


\section{Deactivation and reactivation in acetylene hydrochlorination}

$\mathrm{C}_{2} \mathrm{H}_{2}$ is a well known reducing agent, and we have carried out detailed experiments to determine if the reduction in activity is an effect of the reaction or of acetylene only (20). In order to achieve this, a series of experiments were carried sequentially exposing the catalyst to individual components of the reactants, whilst maintaining the overall contact time in the catalyst bed. To achieve this, an inert gas $(\mathrm{He})$ was added to the reactants to ensure the overall flow rate could be maintained constant. Four sets of experiments were conducted, using a 1:1 molar reactant ratio at $180^{\circ} \mathrm{C}$, as follows:

- Experiment 1: $\mathrm{C}_{2} \mathrm{H}_{2} / \mathrm{HCl}(2 \mathrm{~h}) \rightarrow \mathrm{He} / \mathrm{HCl}$

$(2 \mathrm{~h}) \rightarrow \mathrm{C}_{2} \mathrm{H}_{2} / \mathrm{HCl}(2 \mathrm{~h})$

- Experiment 2: $\mathrm{He} / \mathrm{HCl}(2 \mathrm{~h}) \rightarrow \mathrm{C}_{2} \mathrm{H}_{2} / \mathrm{HCl}$ $(2 \mathrm{~h}) \rightarrow \mathrm{He} / \mathrm{HCl}(2 \mathrm{~h})$

- Experiment 3: $\mathrm{C}_{2} \mathrm{H}_{2} / \mathrm{HCl}(2 \mathrm{~h}) \rightarrow \mathrm{C}_{2} \mathrm{H}_{2} / \mathrm{He}$ $(2 \mathrm{~h}) \rightarrow \mathrm{C}_{2} \mathrm{H}_{2} / \mathrm{HCl}(2 \mathrm{~h})$

- Experiment 4: $\mathrm{C}_{2} \mathrm{H}_{2} / \mathrm{He}(2 \mathrm{~h}) \rightarrow \mathrm{C}_{2} \mathrm{H}_{2} / \mathrm{HCl}$ $(2 \mathrm{~h}) \rightarrow \mathrm{C}_{2} \mathrm{H}_{2} / \mathrm{He}(2 \mathrm{~h})$

The results of these experiments are shown in Figs. 8. The role of $\mathrm{HCl}$ is clearly demonstrated in experiments 1 and 2 . In experiment 1, where the intermediate step is $\mathrm{He} / \mathrm{HCl}$, the catalytic activity is maintained when the acetylene is reintroduced in the third phase of the experiment. In experiment 2 , where the initial treatment is with $\mathrm{He} / \mathrm{HCl}$, on introduction of the acetylene the formation of vinyl chloride is significantly enhanced. In this case, the initial $\mathrm{HCl}$ treatment oxidizes some $\mathrm{Au}^{0}$. Conversely, exposure to $\mathrm{C}_{2} \mathrm{H}_{2}$ leads to catalyst deactivation in the absence of $\mathrm{HCl}$ (experiments 3 and 4), the catalyst was deactivated by exposure to $\mathrm{C}_{2} \mathrm{H}_{2}$. It is clear that both reactants are able to modify the final performance of the catalyst, but in opposing directions: a regeneration/activation role for $\mathrm{HCl}$, while $\mathrm{C}_{2} \mathrm{H}_{2}$ acts to decrease the activity of the catalyst, independent of whether the reaction is occurring. Earlier studies (25) have shown that the catalyst activity can be reactivated by exposure to $\mathrm{Cl}_{2}, \mathrm{HCl}$ and $\mathrm{NO}$ and in all these cases we consider the treatment leads to an enhancement in the $\mathrm{Au}^{3+}$ content of the catalyst.

\section{Concluding comments}

The evidence presented for acetylene hydrochlorination to date supports the initial concept that $\mathrm{Au}^{3+}$ is the active component in the supported gold catalysts. The evidence for this comes from the correlation of catalyst activity with the standard electrode potential and the detailed deactivation and reactivation studies involving $X$-ray photoelectron and Mössbauer spectroscopy. A further point that requires comment is the specificity of $\mathrm{Au}^{3+}$ for the reaction of alkynes in the hydrochlorination reaction. The reaction is very specific indeed and the sequential hydrochlorination of vinyl chloride is not observed. Indeed co-feeding ethene with acetylene will not result in any reaction of the ethene. This specificity has analogies in the homogenously catalysed reactions of alkynes (28) which show high activity just for alkynes. This indicates that there is a potentially rich new catalytic chemistry available for alkynes using heterogeneous catalysts involving $\mathrm{Au}^{3+}$. Indeed, recently Corma and co-workers have shown that new materials based on $\mathrm{Au}^{3+}$ MOFs can be synthesised (29) and these can also show specificity of reactions for alkynes over reactions for alkenes. Hence, there appears to be generality for the specificity of $\mathrm{Au}^{3+}$ for the reaction of alkynes. This gives further support for $\mathrm{Au}^{3+}$ being the active component in the acetylene hydrochlorination reactions. However, the $\mathrm{Au} / \mathrm{C}$ catalysts used to date in this reaction comprise a broad range of particle sizes and the active structures have yet to be identified, it is possible that these may well involve small clusters as identified in the $\mathrm{Au} / \mathrm{Fe}_{2} \mathrm{O}_{3}$ catalyst (16) but the detailed studies have yet to be carried out.

\section{About the author}

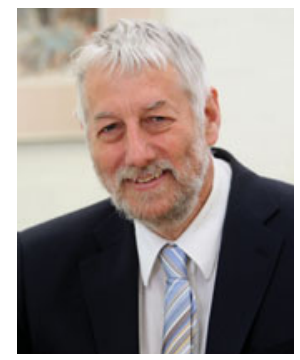

Graham Hutchings is currently Director of the Cardiff Catalysis Institute and Professor of Physical Chemistry at Cardiff University. His early career was spent in industry, in $\mathrm{ICl}$ at Teeside, and then in $\mathrm{AECl}$, South Africa, where he made his initia discoveries concerning catalysis with gold. He moved to academia in 1984, and he has been mainly interested in the discovery of catalysts for oxidation and enantioselective reactions. He has held chairs in the University of Witwatersrand and the University of Liverpool before moving to Cardiff in 1997. He was elected a Fellow of the Royal Society in 2009. 


\section{References}

1 G.C. Bond, D.T. Thompson, Catal. Rev.-Sci. Eng., 1999, 41, 319

2 G.C. Bond, D.T. Thompson, Gold Bull., 2000, 33, 41

3 H.S. Taylor, Proc. R. Soc. (London)., 1925, A108, 105

4 M. Haruta, T. Kobayashi, H. Sano, N. Yamada, Chem. Lett.,1987, 16, 405

5 M. Haruta, Gold Bull, 2004, 37, 27

6 G.J. Hutchings, Catal. Today, 2002, 72, 11

7 M. Haruta, CATTECH 2002, 6, 102

8 J.J. Pietron, R.M. Stroud, D.R. Rolison, Nano Lett. 2002, 2, 545

9 J. Guzman, B.C. Gates, J. Am. Chem. Soc. 2004, 126, 2672

10 G.J. Hutchings, M.S. Hall, A.F. Carley, P. Landon, B.E. Solsona, C.J. Kiely, A. Herzing, M. Mckee, J.A. Moulijn, A. Overweg, J.C. Fierro-Gonzalez, J. Guzman and B.C. Gates, J. Catal. 242, 71 (2006)

11 M.M. Schubert, S. Hackenbergs, A.C. van Veen, M. Muhler, V. Plzak, R.J. Behm, J. Catal. 2001, 197, 113

12 R. Meyer, C. Lemire, Sh. K. Shaikhutdinov, H.J. Freund, Gold Bull. 2004, 37, 72

13 M. Valden, X. Lai, D.W. Goodman, Science 1998, 281, 1647

14 M.S. Chen, D.W. Goodman, Science 2004, 306, 252

15 D. Matthey, J.G. Wang, S. Wendt, J. Matthiesen, R. Schaub, E. Laegsgaard, B. Hammer, F. Besenbacher, Science 315, $1692(2007)$

16 A.A. Herzing, C.J. Kiely, A.F. Carley, P. Landon, G.J. Hutchings, Science, 2008, 321, 1331
17 G.J. Hutchings, Dalton Trans., 2008, 5523

18 J.K. Edwards, G.J. Hutchings, Angew. Chem. Int Ed., 2008, 47, 9192

19 M. Conte, A.F. Carley, G.J. Hutchings, Catal. Lett., 2008, 124, 165

20 M. Conte, A.F. Carley, C. Heirene, D.J. Willock, P. Johnston, A.A. Herzing, C.J. Kiely, G.J. Hutchings, J. Catal., 2007, 250, 231

21 M. Conte, A.F. Carley, G. Attard, A.A. Herzing, C.J. Kiely, G.J. Hutchings, J. Catal., 2008, 257, 190

22 G.J. Hutchings, J. Catal., 1985, 96, 292

23 B. Nkosi, N.J. Coville, G.J. Hutchings, J. Chem. Soc., Chem. Commun., 1988, 71

24 B. Nkosi, N.J. Coville, G.J. Hutchings, Appl. Catal., 1988, 43, 33

25 B. Nkosi, N.J. Coville, G.J. Hutchings, M.D. Adams, J. Friedl, F. Wagner, J. Catal., 1991, 128, 366

26 D.I. Enache, J.K. Edwards, P. Landon, B. Solsona-Espriu, A.F. Carley, A.A. Herzing, M. Watanabe, C.J. Kiely, D.W. Knight and G.J. Hutchings, Science, 2006, 311, 362

27 J.K. Edwards, B. Solsona, E. Ntainjua, N.A.F. Carley, A.A. Herzing, C.J. Kiely, G.J. Hutchings, Science, 2009, 323, 1037

28 A.S.K. Hashmi and G.J. Hutchings, Angew. Chem. Int. Ed., 2006, 45, 7896

29 X. Zhanga, F.X. Llabrés, Xamena, A. Corma, J. Catal., 2009, 265, 155 